\title{
Implementing continuity of midwife carer - just a friendly face? A realist evaluation
}

\author{
Rhona J. Mclnnes ${ }^{1 *}$, Alix Aitken-Arbuckle ${ }^{2}$, Suzanne Lake ${ }^{3}$, Caroline Hollins Martin² and Juliet MacArthur ${ }^{4}$
}

\begin{abstract}
Background: Good quality midwifery care saves the lives of women and babies. Continuity of midwife carer (CMC), a key component of good quality midwifery care, results in better clinical outcomes, higher care satisfaction and enhanced caregiver experience. However, CMC uptake has tended to be small scale or transient. We used realist evaluation in one Scottish health board to explore implementation of CMC as part of the Scottish Government 2017 maternity plan.

Methods: Participatory research, quality improvement and iterative data collection methods were used to collect data from a range of sources including facilitated team meetings, local and national meetings, quality improvement and service evaluation surveys, audits, interviews and published literature. Data analysis developed contextmechanism-outcome configurations to explore and inform three initial programme theories, which were refined into an overarching theory of what works for whom and in what context.

Results: Trusting relationships across all organisational levels are the context in which CMC works. However, building these relationships during implementation requires good leadership and effective change management to drive whole system change and foster trust across all practice and organisational boundaries. Trusting relationships between midwives and women were valued and triggered a commitment to provide high quality care; CMC team relationships supported improvements in ways of working and sustained practice, and relationships between midwives and providers in different care models either sustained or constrained implementation. Continuity enabled midwives to work to full skillset and across women's care journey, which in turn changed their perspective of how they provided care and of women's care needs. In addition to building positive relationships, visible and supportive leadership encourages engagement by ensuring midwives feel safe, valued and informed.

Conclusion: Leadership that builds trusting relationships across all practice and organisational boundaries develops the context for successful implementation of CMC. These relationships then become the context that enables CMC to grow and flourish. Trusting relationships, working to full skill set and across women's care journey trigger changes in midwifery practice. Implementing and sustaining CMC within NHS organisational settings requires significant reconfiguration of services at all levels, which requires effective leadership and cannot rely solely on ground-up change.
\end{abstract}

Keywords: Midwifery, Continuity of carer, Organisational change, Service reconfiguration, Evidence based care

\footnotetext{
*Correspondence: r.mcinnes@griffith.edu.au

${ }^{1}$ School of Nursing \& Midwifery, Griffith University, Gold Coast Campus, Gold

Coast, Queensland, Australia

Full list of author information is available at the end of the article
}

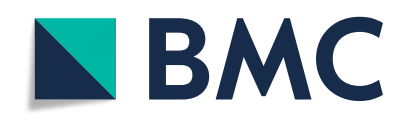

() The Author(s). 2020 Open Access This article is licensed under a Creative Commons Attribution 4.0 International License, which permits use, sharing, adaptation, distribution and reproduction in any medium or format, as long as you give appropriate credit to the original author(s) and the source, provide a link to the Creative Commons licence, and indicate if changes were made. The images or other third party material in this article are included in the article's Creative Commons licence, unless indicated otherwise in a credit line to the material. If material is not included in the article's Creative Commons licence and your intended use is not permitted by statutory regulation or exceeds the permitted use, you will need to obtain permission directly from the copyright holder. To view a copy of this licence, visit http://creativecommons.org/licenses/by/4.0/. The Creative Commons Public Domain Dedication waiver (http://creativecommons.org/publicdomain/zero/1.0/) applies to the data made available in this article, unless otherwise stated in a credit line to the data. 


\section{Background}

Good quality midwifery care saves the lives of women and babies, with continuity of midwife carer (CMC) a key component of this [1]. A growing body of evidence, including a Cochrane review of 17 randomised controlled trials of over 17,000 women [2] shows that, compared to fragmented models of care, CMC results in better, or at least as good, outcomes and greater maternal satisfaction [2-6]. Despite this evidence, fragmented maternity care remains dominant in many countries and efforts to implement CMC have tended to be small scale, slow to grow or not sustained [4].

In CMC women are allocated a named or primary midwife who provides all midwifery care through pregnancy, birth and the postnatal period. This differs from fragmented models where women receive care from different midwives depending on stage of childbearing, risk factors, their location and local services [2]. Around the world CMC has been implemented in different contexts with variation in: composition of the multidisciplinary team (MDT); degree of autonomous practice, and target populations, all of which will impact on implementation, outcomes and sustainability [2].

Various CMC models, such as Midwifery Group Practice (MGP), caseload, independent or team midwifery, offer different opportunities for a known midwife to provide care. For example, MGP or independent practice midwives provide all care, including being on-call for their own caseload births, whereas team midwives provide antenatal and most postnatal care for their own caseload but are on-call for all births in the team [2, 3]. Thus women in MGP or independent models are more likely to already know the midwife attending their birth. It is as yet unclear if this makes a difference to any outcomes. All continuity models have better outcomes than fragmented care models but there is no consistent evidence that one type of continuity model is better than another [2].

Our literature scoping identified several countries attempting to grow CMC as a nationally available model of midwifery care. In the last decade, Australia has introduced government policy, legislation and midwifery education standards to re-orientate maternity services to ensure more women have access to CMC [7]. Despite this, changes to mainstream service delivery and expansion of existing midwifery continuity models remains slow with reports of less than 10\% [7] to 19\% [8] of Australian women having access to CMC. New Zealand legalised midwives as autonomous health professionals and as Lead Maternity Carers (LMC) in 1990, enabling them to care for a caseload of women. Midwives can be hospital and/or community based, with most community-based midwives self-employed and contracting directly with the Ministry of Health (see [9]). Women choose who to engage as their
LMC (midwife, GP or obstetrician), with most (over $80 \%$ in 2015) choosing a midwife [10]. In Denmark, where midwifery-led practice has been the standard for all women since midwives were 'authorised' 300 years ago, caseload midwifery has become increasingly popular with around $24 \%$ of childbearing women being offered it in some areas [11]. Midwives generally work in pairs, each having a caseload of around 60 women per year, and are on call for their or their partner's caseload [11]. CMC is a key component of current United Kingdom (UK) maternity plans e.g. The Best Start in Scotland [12] and Better Births in England [13]. The importance of CMC has been acknowledged in the UK since the 1993 publication of Changing Childbirth [14], however implementation was often small scale or not sustained. Thus, despite our knowledge of $\mathrm{CMC}$ as a superior model of care, the known risks associated with fragmented care and ongoing efforts to drive change, its uptake is slow and patchy. Understanding how CMC works might help to normalise it as a sustainable model of care.

This study uses realist evaluation in one Scottish health board to explore how CMC works, for whom, in what context and to what extent, and so inform sustainable on-going implementation and up-scaling within the context of The Best Start [12].

\section{Methods}

Realist Evaluation (RE) is a theory driven approach which aims to understand how complex interventions, such as CMC, work. RE goes beyond answering if a programme works to answer how it works, for whom, to what extent and under what circumstances [15]. Programmes work by enabling or motivating individuals to change their reasoning or behaviour [16]. People's responses vary according to circumstances, which is why interventions work in some contexts but work differently or not at all in others and explains why interventions cannot simply be transferred to another context and expected to achieve the same outcomes [16]. In RE 'mechanisms' are the responses which are triggered in various circumstances to produce specific outcomes [15] and understanding these is fundamental to RE [17]. The interaction between circumstances and mechanisms is frequently presented as Context + Mechanism $=$ Outcome (CMO) [16]. RE recognises that the theory-based understanding of how a programme works can be replicated in different contexts [16], which is particularly useful for upscaling programmes, such as CMC, that have been shown to work in some contexts. RE's sensitivity to context, which influences how an intervention unfolds, makes it appropriate for trying to establish what conditions and factors are pre-requisites for embedding CMC into routine care and ensuring positive outcomes [18]. 


\section{Setting - National Context}

In Scotland, and other UK countries, NHS maternity services are provided free of charge and most midwives practise in the NHS and are bound by NHS 'Agenda for Change' terms and conditions [19] and government strategies or policies. A very small number of women are cared for privately by an independent midwife. Midwives are the first point of contact for all women, the lead carer for 'low risk' women and care coordinators for women with additional risk factors or complex needs, where the obstetrician would be the lead carer [20]. Antenatal (AN) care is usually provided in primary care or hospital settings or occasionally at home; women can birth their baby at home, in a freestanding or alongside midwife-led unit or in hospital; immediate postnatal (PN) care is initially in the birth location and then in the woman's home for up to around 10 days. Care is frequently fragmented by location and care provider according to stage of pregnancy, medical or obstetric risk factors, maternal choice and the availability of facilities.

There are significant concerns about the UK midwifery workforce including high levels of stress, sickness and poor workplace cultures [21]. These factors, along with feeling unable to provide good quality care and disliking the current fragmented model, are driving midwives out of the profession [22, 23]. The 2018 State of the Maternity Services Scotland [24] report highlighted increasing midwifery vacancies (quadrupled in the previous 5 years); more vacancies remaining unfilled, and an increase in midwives leaving the profession. Although birth rates have fallen over the past 3 years more women are presenting with increasingly complex needs including pre-existing medical conditions, obesity and giving birth later in life (54\% of babies in Scotland are born to women over 30 years).

\section{Local context}

This study was set in one Scottish health board, which is served by two maternity hospitals and has around 9500 births per year. Previous attempts to introduce CMC in this area were small scale and not sustained. Our baseline survey [25], developed to understand the local context, highlighted that local midwives supported the principles of CMC but opposed its implementation [26]. We used the ecological model [27] to organise survey findings and examine factors at the micro, meso and macro levels, which was helpful for showing how influences at various organisational levels can impact on the clinical experiences of midwives and ongoing implementation and sustainability of CMC, Table 1.

\section{The Best Start continuity model}

The Best Start plan [12] was informed by published evidence and national consultation with key stakeholders including women and midwives. Following publication, health boards could apply to be 'early adopters' to test implementation with some anticipating this would bring resources. Early adopter status was approved in September 2017 and despite no accepted definitions, evaluation tools or clear indication of additional resources an early, and ambitious, target proposed that CMC be achieved for $75 \%$ of women within 2 years.

The Best Start [12] advocates teams of 6-8 midwives each with Full Time Equivalent (FTE) caseloads of 35

Table 1 The local context for introduction of $\mathrm{CMC}^{*}$

\begin{tabular}{|c|c|}
\hline Potential Facilitators & Potential Barriers \\
\hline \multicolumn{2}{|l|}{ Macro (organisation): } \\
\hline $\begin{array}{l}\text { High level support for new model. Clinical outcomes relatively good } \\
\text { but rising intervention and decreasing 'normal' birth drive the need } \\
\text { to change. Women generally satisfied with care but want more } \\
\text { opportunities to build relationships with midwives. }\end{array}$ & $\begin{array}{l}\text { Shortage of resources, funds \& community-based facilities. Current sys } \\
\text { tems embedded in and developed for the fragmented model. Midwives } \\
\text { leaving and fewer attracted in - leading to local and national shortages. }\end{array}$ \\
\hline \multicolumn{2}{|l|}{ Meso (practice context) } \\
\hline $\begin{array}{l}\text { Experience varies by location but good AN continuity within some } \\
\text { community teams, while others recognise a need to improve. High } \\
\text { stress and poor work experience may facilitate change, i.e. midwives } \\
\text { will want to work differently }\end{array}$ & $\begin{array}{l}\text { Lack of consistent access to physical spaces for clinical practice. Increasing } \\
\text { work load, poor work-life balance and high stress among midwives - may } \\
\text { constrain change i.e. midwives feel too stressed or burnt out to consider } \\
\text { change. Poor relationships within and between professional groups. }\end{array}$ \\
\hline \multicolumn{2}{|l|}{ Micro (midwife, relationship with women) } \\
\hline $\begin{array}{l}\text { Some midwives welcome opportunities to build relationships and for } \\
\text { holistic, woman centred practice. Some have had experiences of CMC. } \\
\text { Limited opportunity for continuity \& developing good relationships in } \\
\text { current model but wanted by women and some midwives. Newly } \\
\text { qualified midwives have positive experiences of CMC during } \\
\text { undergraduate education. }\end{array}$ & $\begin{array}{l}\text { Most midwives want to stay in fragmented model. Many express } \\
\text { concerns about safety of new model (e.g. not having right skills in right } \\
\text { place), its impact on personal life or that it will not be properly resourced. } \\
\text { Most midwives comfortable with rostered shifts and managing their work } \\
\text { within these distinct periods. Many believe relationships with women are } \\
\text { already good, or that women get too much choice or expect too much. } \\
\text { Many do not believe new model to be very different to current care or to } \\
\text { offer better continuity }\end{array}$ \\
\hline
\end{tabular}

* Macro = actions \& interactions at organisational \& managerial levels and with midwives \& MDT at other levels; Meso = actions and interactions within the CMC team, between CMC and non-CMC midwives and others in the MDT; Micro = actions and interactions between women and midwives and individual midwife attitudes \& beliefs. Source: informal discussions, stakeholder interviews, baseline survey 
women at any given time (i.e. around 40-42 per year). Women are allocated a 'primary' midwife who provides continuity, with support from the team and/or a 'buddy' midwife. Operationalising CMC has varied across the 14 Scottish health boards according to local facilities and concurrent care structures. In most health boards, midwives were encouraged to develop a way of working to suit their team while ensuring 24-h cover for team births through a combination of rostering and on-call. In our study area CMC started as a 'test of change' with a small team of midwives (6 FTEs), who volunteered to trial the model within the context of the dominant fragmented model [12].

\section{Data collection, sources \& analysis}

As clinical academics within the board, the researchers supported the design of service evaluation tools to monitor staff and women's experience as part of the test of change. This involved regularly attending team meetings to facilitate reflective practice sessions to develop a force field analysis of the key factors affecting implementation and staff experience. Gibb's reflective cycle [28] underpinned the process, which itself became highly valued by the CMC midwives, aligning to the perceived benefits of the refreshed model for clinical supervision [29] such as enhanced self-awareness, problem solving skills and resilience. In particular, the team acknowledged the benefit of reflecting together for promoting positive team dynamics. In addition to facilitating reflection, we were also able to provide information from local and national implementation meetings and signpost supporting resources, to assist the team with their implementation of the evolving CMC model; e.g. practice ideas and approaches being tested in other health boards. Each meeting was written up, approved by the CMC team and shared with local health board. We also attended local and national policy and implementation meetings and local working groups that aimed to operationalise the model of care. Data sources are summarised in Table 2.

\section{Recruitment of interview participants}

Interview participants were purposively recruited to reflect their roles within the implementation process, Table 2. Participants were invited by email, word of mouth or flyer and provided written consent prior to taking part. A realist evaluation informed topic guide was developed to steer the interviews (Additional File 1).

The limited resource and time available to allow effective use of the developing evaluation process to inform implementation was challenging. Implementation was intended to be based on the Model for Improvement [30] but the iterative improvement cycles often became complicated by other changes, either at local or national level, as the CMC political landscape continually evolved. Implementation of the continuity model,

Table 2 Data Sources

\begin{tabular}{|c|c|c|c|}
\hline Source & Number & Dates & Type of data \\
\hline \multicolumn{4}{|c|}{ Sources informing initial programme theories } \\
\hline Published literature & & From Nov 2016 & Papers and reports \\
\hline Stakeholder interviews & 4 leaders at macro level & June - Sept 2017 & Interview transcripts \\
\hline Baseline survey & 321 midwives responded & Oct - Dec 2017 & Survey data including free text \\
\hline Participant observations & Local and national events & From Jan 2017 & Field notes \\
\hline \multicolumn{4}{|c|}{ Sources for testing programme theories (in addition to above) } \\
\hline $\begin{array}{l}\text { Facilitated CMC Team } \\
\text { Meetings }\end{array}$ & 12 meetings & $\begin{array}{l}\text { Dec } 2018 \text { - Aug } \\
2019\end{array}$ & Field notes \& summaries \\
\hline CMC team surveys & $\begin{array}{l}15 \text { (Team 1: } 11 \text { surveys, } 50 \text { responses; Team 2: } 2 \text { surveys, } \\
18 \text { responses) }\end{array}$ & Jan -Sept 2019 & Quality improvement survey data \\
\hline $\begin{array}{l}\text { Local implementation } \\
\text { meetings }\end{array}$ & & $\begin{array}{l}\text { Feb } 2017-\text { Sept } \\
2019\end{array}$ & Field notes \\
\hline $\begin{array}{l}\text { National implementation and } \\
\text { leader meetings }\end{array}$ & & $\begin{array}{l}\text { May } 2018-\text { Sept } \\
2019\end{array}$ & Field notes \\
\hline $\begin{array}{l}\text { Women receiving } \mathrm{CMC} \text { from } \\
\text { local teams }\end{array}$ & 89 women & Feb - Nov 2019 & $\begin{array}{l}\text { Service evaluation questionnaire data } \\
\text { including free text }\end{array}$ \\
\hline $\begin{array}{l}\text { Wider workforce not in CMC } \\
\text { team }\end{array}$ & 36 midwives: 12 community and 24 hospital based & Feb- March 2019 & Audit data \\
\hline Participant observations & National stakeholder events & $\begin{array}{l}\text { March } 2017 \text { and } \\
\text { May } 2019\end{array}$ & Field notes \\
\hline $\begin{array}{l}\text { One-to-one midwife } \\
\text { interviews }\end{array}$ & $\begin{array}{l}9 \text { midwives: } 4 \text { leaders ( } 3 \text { not in health board); } 2 \text { in CMC } \\
\text { teams; } 3 \text { in standard model. }\end{array}$ & May - Aug 2019 & Interview transcripts \\
\hline
\end{tabular}


collection of our evaluation data and analysis were therefore 'messy', iterative processes which frequently interacted as we went to and fro between a range of data sources, including experiential data, within a changing landscape, to identify, develop and test theories, Fig. 1.

\section{Analysis}

RE begins with a programme theory, which is basically the premise within an intervention that if we do $\mathrm{X}$ we bring about change $\mathrm{Y}^{\prime}$ [31]. Most programmes or interventions have a theory but do not always make this explicit. The first stage of our analysis was to identify candidate or initial programme theories. In our study these were informed by The Best Start document [12], the published literature, published and unpublished reports, local policies, listening to midwives' responses to the publication of The Best Start [12] at formal and informal sessions and through interviews with policy and organisational level stakeholders. These theories were then tested and refined through data collection and analysis using the data sources outlined above, Table 2. Testing assesses if our expectations of how the programme works are true and, if not, enables us to explore why [32]. We developed 20 'if ...then' statements linking CMC to potential outcomes (Additional File 2) and, through discussions at team meetings, developed three CMO configurations (Additional File 3) as theories, which we tested during on-going implementation of CMC. 'If-then' statements form the initial steps linking programme elements with outcomes and have been used widely in realist studies [32]. Interviews were transcribed verbatim and uploaded into QSR NVivo (Version 12) along with meeting summaries, field notes, service evaluation and audit data. Data were coded according to our CMO configurations, either as part or whole CMOs. During testing and on-going implementation, we identified additional 'if ...then' statements that explained some of the outcomes within our context, (Additional File 4).

\section{Ethics}

We obtained ethical approval to conduct interviews and to use quality improvement and audit data in our research. We were advised that we did not need NHS Ethics review due to the nature of our data collection and participants. Ethical approval was therefore obtained from Edinburgh Napier University (SHSC 18014) with the main ethical issue being the risk of identifying participants from the CMC team, thus requiring careful management of confidentiality and protection of identity.

\section{Results}

This section outlines the initial programme theory and then presents three inter-related programme theories (relationships, midwifery practice, and leadership and support) that were tested and drawn together into a refined programme theory that articulates the context, mechanisms and outcomes of successful CMC implementation. All data and quotes are identified by their source. To maintain anonymity midwives' interviews are numbered 1-9 rather than by specific role or location,

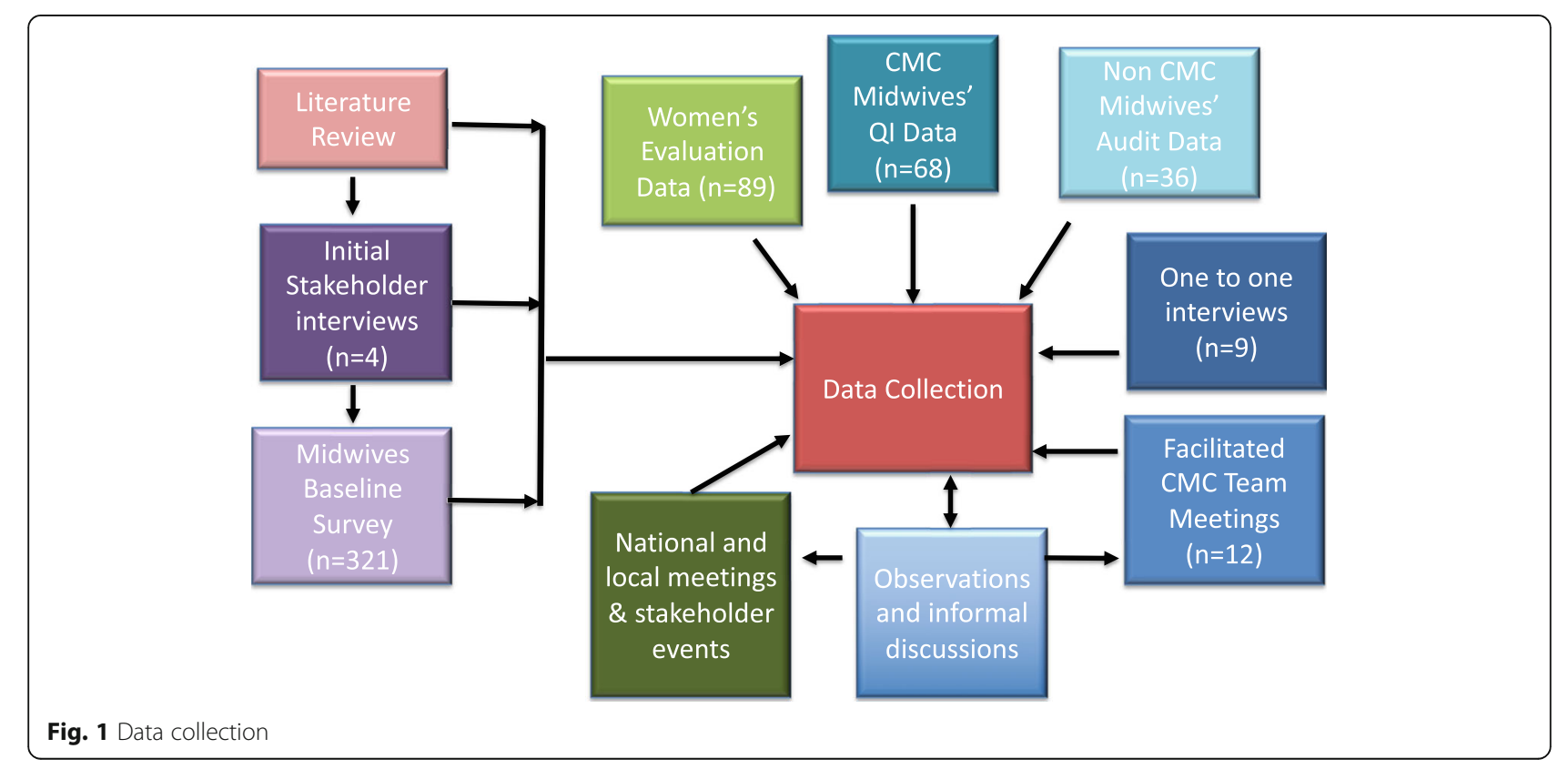


except where including role provides important context (and number is omitted).

\section{Initial Programme theory}

The overarching theory is that CMC will improve clinical outcomes, increase care satisfaction and improve care giving experiences by changing the dominant model of care from a fragmented to a relationship-based model, which aligns with the published literature as discussed. The actual mechanisms by which CMC leads to better outcomes are not fully recognised, but where tested CMC reduces interventions and enhances normal physiological processes such as normal birth and breastfeeding. Causal mechanisms could potentially involve biopsychosocial interactions; for example, the complex hormonal interactions during pregnancy and birth are affected by socio-emotional factors, which are affected by relationships [33]. CMC provides opportunities for midwives and women to build relationships and get to know each other through repeated care contacts and for midwives, through being responsible for all midwifery care, to work autonomously to full scope of practice. The Best Start [12] also recommends aligning obstetric staff to midwifery caseloads to build professional relationships and collaborative working.

According to The Best Start's theory several factors (relationships, full scope of practice, autonomy and collaborative working) might potentially act and interact to affect clinical outcomes and sustainability. In the literature, two key constructs dominated authors' discussions of how CMC might result in better care experiences and outcomes and these aligned with our initial stakeholder interviews. These were relationships (midwife-woman; midwife-midwife, midwife-MDT and within the organisation) and how midwives practise (autonomous, flexible and to full scope of midwifery practice). In addition, stakeholders and some published papers highlighted the importance of good leadership and effective change management to enable $\mathrm{CMC}$ to be accepted and embedded in practice. The three programme theories are presented below, with the final $\mathrm{CMO}$ configurations in Table 3 and supporting evidence in Table 4.

Initially, due to their dominance in the published literature and in The Best Start, we assigned relationships to the first programme theory. However, following our testing in the implementation context we believe that 'leadership and support' is the most influential and it is in the context of effective leadership that trusting relationships and practice change are triggered.

\section{Programme theory 1: leadership and support}

Organisational contextual factors can facilitate or constrain implementation [34-39] and these were reflected in our evaluation. Leadership, support from management and effective change management processes are hugely important during implementation [35, 39] and have also been shown to positively impact on midwives' wellbeing [40]. Lack of good leadership with poor communication or failure to listen to concerns leaves midwives feeling undermined and unsupported. This leads to poor support for CMC across all levels of the organisation and restrains the development of trusting relationships. Pressure to make CMC work might reflect targets and timelines set by government, which combined with lack of resources, played out across all levels of the organisation including individual beliefs (micro)

I'm not averse to it once things have been ironed out, but people need to listen to the midwives and keep touching base with the midwives, and the impression I get is it's like 'well you haven't met this target, you haven't done this, you're supposed to be doing this', as opposed to 'why haven't you managed that, what's going on, what can we do to help, what can we make easier, how do we iron this out?' and that's not the impression I'm getting from them, it's that 'you haven't done this, you haven't done that, you haven't done this either and why hasn't that been done yet?' and that's no way to work, it's no way to live. (Midwife Interview 6)

For CMC midwives in our study, organisational pressure to perform well [41] combined with micromanagement [42] stifled flexibility and undermined autonomous practice. As has been found elsewhere, lack of support and poor practice arrangements [43, 44] counteracted possible benefits and impacted negatively on midwives' wellbeing and sustainability of CMC. In our study, as in others, there was (considerable) workforce resistance to change $[36,39,42]$ much of which was predicated on concern about impact on personal lives and ultimately on wellbeing (Baseline Survey).

Good leadership of change management needed for $\mathrm{CMC}$ requires belief, shared vision and effective and consistent communication. During our evaluation, inconsistencies in beliefs at all levels affected how people engaged with $\mathrm{CMC}$, e.g. whether to volunteer or to support implementation from within the wider workforce. Lack of belief in CMC or The Best Start was sometimes visible through inaction, reluctance to provide assistance or support, poor practice or incongruence between verbal and non-verbal communication.

\section{Refined theory 1: leadership}

Good leadership builds trusting relationships which make staff feel safe, able to engage and practise autonomously thus supporting on-going implementation. Visible leadership provides shared visions and goals 
Table 3 Refined CMO configurations

\section{CMO1: Good leadership builds trusting relationships which make staff feel safe, able to engage and practise autonomously thus} supporting on-going implementation

$\begin{array}{ll}\text { CONTEXT } & \text { MECHANISM } \\ \text { Leaders (organisation \& policy) enact their vision } & \text { Organisation Leaders (MACRO) } \\ \text { \& belief in CMC by: } & \text { - Direct resources to enable CMC } \\ \text { - Visible leadership } & \text { - Challenge attitudes or behaviours that don't support high quality } \\ \text { - Congruence between vision and action } & \text { care } \\ \text { - Appropriate resourcing of new model, } & \text { Midwives (MESO) } \\ \text { including time, support } & \text { - Feel safe, supported and reassured } \\ \text { - Trusting staff to be responsible / autonomous } & \text { - Are motivated and empowered to engage } \\ & \text { - Trust the process of change will be well managed and properly } \\ & \text { resourced } \\ & \text { - Trust each other } \\ & \text { - Feel heard and understood }\end{array}$

OUTCOME

MACRO

- Positive work place

culture

- Retention of staff

- Sustained implementation of CMC

$\mathrm{MESO} / \mathrm{MICRO}$

- Role satisfaction

- Wellbeing

CMO2: In the context of effective leadership CMC provides opportunities to build more trusting relationships between midwives \& women, at all levels of the organisation, which trigger changes in behaviours and practice.

\section{CONTEXT}

MICRO (woman-midwife) regular and repeated contact across the childbearing enable a relationship where:

- Trust develops

- Women don't have to repeat their story so provide more information at care appointment

- Midwives more informed and familiar with woman's context

- Women better informed about their care
MECHANISM

Women

- Feel known, understood \& accepted rather than watched or judged,

- Feel confident in their midwife's abilities

- Disclose more personal information \& seek more information

- Believe in/trust their midwife

- Engage with health services and health advice

- Feel empowered, confident in own abilities to birth \& nurture their infant

-Women \& midwives feel relaxed and less anxious;

Midwives

- More informed about women's circumstance, plan womancentred, appropriate care, timely detection of changes requiring treatment or referral

- Develop flexible con safe and cared for

- Feel accepted rather than watched or judged

- Feel confident, relaxed \& less anxious about practice

- Are able to ask for help or support, particularly in challenging

situations

- Communicate openly \& honestly about personal \& professional

challenges (make CMC work for all midwives)

- Value and care for each other

- Supported and empowered to provide high quality care

- Feel valued, cared for, supported and empowered

- Trusted to be in control of diary, workload and so able to provide

flexible woman centred care

- Motivated to engage with and support new model
PROXIMAL OUTCOMES

- Hormonal regulation optimises biopsychosocial processes

- Health service engagement and healthy lifestyle choices

- Woman centred care

DISTAL OUTCOMES

- Improved maternal \&

foetal wellbeing

- Reduced clinical intervention

- Increased breastfeeding

- Increased satisfaction with care

- Midwife role satisfaction and better emotional wellbeing

- Midwife role satisfaction

- Good work life balance

- Reduced stress and anxiety

- Safe high-quality care

- Implementation of CMC

- Safe high-quality care

- Woman centred care

- Autonomous practice

- Implementation of CMC

- Positive workplace culture

- Retention of staff

- Open supportive communication

CMO3: in the context of good leadership, trusting relationships and autonomous practice midwives use the full scope of midwifery practice to provide flexible, woman-centred evidence-based care.

CONTEXT

Shared belief in the values and philosophies of

CMC across organisation ensuring:

- Relationship based care across the childbearing journey

- Autonomous, responsible midwives practicing

to full scope of midwifery

- Choice of role / location

- High quality evidence based care.
MECHANISM

- Motivated to engage with CMC

- Seek out best quality evidence to inform care

- Reflect on consequences of care decisions \& experiences to inform future care

- In control of diaries, planning \& flexible working

- Provide home based care: empowering for women, build relationships

- Provide expert, information \& emotional support to women, midwives \& MDT

- Direct resources to enable CMC

- Challenge attitudes or behaviours that don't support high quality care
OUTCOME

- High quality evidence-

based care

- Good clinical outcomes

- Role satisfaction

- Wellbeing

- Positive work place

culture

- Retention of staff

- Sustained implementation of CMC 
Table 4 Evidence for cmo configurations

\section{1: Leadership and support}

No I think it is down to leadership. Leadership at board level but then also the heads of midwifery giving leadership roles to appropriate people and giving them enough time to lead implementation; I think that's really key as well ... but that the senior leaders have vision and drive and are really wanting it to happen so they are helping motivate that devolved leadership I think (Midwife Interview 1)

The senior managers who are I appreciate following government initiatives that are actually to implement this, but I think there's a bit of a, I would say there's a lack of faith. INT: What d'you think drives the lack of faith? RES: People don't trust what's going on. [...] This feels very invisible, even though there's lots of communication about it, it's the nuts and bolts, people want to know how is this going to affect me? (Midwife Interview 3)

I work in a board that's very, very supportive of each other and any change, this is transformational change, but in any change we have a good I suppose executive nurse director and good lead and work as a team so therefore, and she's very, very robust in the way that she carries any project through (Midwife Interview 4)

It felt like they issued this report [Best Start] that this change is happening and that's it and we've got to make it happen, and there was just very little information, had to sort of make it up as they went along. (Midwife Interview 5)

Could there have been stages to the strategy, could there be a bit more instruction with the strategy about how this would be implemented? I know there were timelines but there wasn't even a year to prepare, it was like 'right, get on with it'. So I feel... so then the strategy has come out without people expecting it and then there wasn't even time to talk to people about how they felt about it. (Midwife Interview 7)

The team highlighted that having an approachable line manager 'makes a difference' to the transitioning to the new model. They highlighted how supported they felt and indicated that without this support and approachability they would have found the process significantly more challenging. (Summary of Facilitated CMC Team Meeting (FCTM) Jan 2019)

There is a strong belief among the midwifery workforce that implementation of $\mathrm{CoC}$ will not happen. The resistance and concerns that were identified in the midwives baseline survey have not dissipated. The midwives are anxious and desperate for information about how a future model might work, were it to be implemented. (Summary of FCTM Jan 2019)

\section{2: Trusting relationships}

It was great to have continuity of care which made me feel safe and listened to (Women's Evaluation)

We had such a positive experience of pregnancy and birth, thanks to [the team]. Going into the labour room and being greeted by a familiar face was invaluable, and we felt so well cared for and supported. (Women's Evaluation)

Having the same midwife for me made the experience better than what it was like having my fist [sic] child. I built a great relationship with [name] and throughout my labour she knew exactly the way I wanted things done. (Women's Evaluation)

Had excellent midwifery care. There was a sense of investing in a relationship which made a positive difference to my birthing experience. I also felt confident as my midwife is experienced on labour ward (Women's Evaluation)

Team members are increasingly using each other for moral support. Each member is developing their own support network within the team (and for some outwith), and there is a strong sense of mutual respect and consideration for all members (Summary of FCTM Jan 2019) The team are really noticing the benefit of getting to know the women, and in their own environment. They report on the satisfaction this gives them in terms of being able to better relate to and understand the women's preferences and needs, which helps them advocate better for the women, and the 'nice' feeling associated with developing a good working therapeutic relationship; the type of relationship they give high value to as part of good professional practice. (Summary of FCTM Feb 2019)

I think what's really important as well is that midwives need to be treated as respected professionals and adults, they also need to behave
Table 4 Evidence for cmo configurations (Continued)

in that way but that often, that hasn't been how services have been run and how midwives have experienced being a midwife, and so I think that means that we don't get the best from them and how they could practice (Midwife Interview 1)

So the midwife getting to know the woman and how she is and her behaviours and her background and her history so that it's easier for the midwife to pick up any changes, I think that's important, I think that would make a difference and I think also for the woman to have built up that relationship and trust already with a midwife and she feels comfortable with her, if there are any changes that she can disclose them, she feels comfortable to act, for example in labour, she feels more comfortable and relaxed because she's got the midwife that she knows and trusts (Midwife Interview 5)

You're never going to be, like, one team with the people in the hospital cause they're based in the hospital and that's what they do all the time and they don't, they're not with you all the time, they don't know what your work's like on a day to day basis, you know, it is just being part of a separate team. And then they're always going to have so many midwives that come in once it's up and running, you know, I think it'd be quite difficult for them to get to know everyone and for it to feel like all one big happy family sort of thing. So I think it'll always feel like you're going into someone else's workplace rather than... (Midwife Interview 9)

\section{3: Practice change}

They're thinking about their practice and that's [improving continuity] just an example of one of the things that they're doing differently (Midwife Interview 4)

So that [sickness in CMC team] provided opportunities for some midwives to go out and just cover for a short couple of weeks and one of the midwives didn't want to come back, ... actually none of the midwives wanted to come back and they've continued to work on that model, and because they're coming into the hospital and working they're talking to other midwives and we're now getting quite a surge of midwives who want to work within the continuity models (Midwife Interview 4)

Yeah it's a different experience. You get to know the woman in her home and how she is in her own environment which I think is important, what her environment is and I think when they let you into their home then that's again building up another layer of trust. (Midwife Interview 5)

If you know the women better hopefully, I would imagine that means that then you have a much better understanding of that woman's needs, her life, her home, her everything that then your care is more tailored to her and that presumably then has some impact on the outcomes. (Midwife Interview 7)

And I think it's [home visit] really important in changing the way that women view their pregnancies, ... I think that by having all their checks with a midwife in a very clinical space that they feel the need to be in a clinical space when they need help, ..., so I think early labour, ... that women who want to see a midwife and they don't feel comfortable being at home and they feel like they need to go into the hospital because they feel like they need something and they shouldn't be at home. So ..., I feel like our women have definitely been... I don't think they've been going into the hospital as early and being sent home as often as the women I used to have and I feel like... Yeah, like, niggling or contracting regularly but they're still quite mild, ... so I don't know if the women are feeling just more comfortable being in their own homes in labour and if they're in labour during the day, like, we're going out to pop in and be like 'is everything okay, stay away from triage, don't go in till you're ready' sort of thing. (Midwife Interview 9) Women seem more relaxed not being in a clinical environment and divulge more (Summary of FCTM Jan 2019)

The significant majority of the team prefer the increased autonomy they have in relation to managing their work life. Being able to work from home, managing own diary and to an extent, working pattern, have been reported as positives and a few feel returning to shifts would now feel very constrained. However, others continue to find it difficult to get the balance (Summary of FCTM April 2019)

The team are beginning to appreciate the enhanced job satisfaction working this model will be able to provide. They are enjoying the 
Table 4 Evidence for cmo configurations (Continued)

relationship the model enables them to build with the women and flexibility in the care they are able to provide (Summary of FCTM Jan 2019)

One of the most significant themes ... is the feeling of isolation within the labour ward; being in a room caring for a woman, not entirely sure of care management, equipment, or processes and not feeling able to access peer support if it is not proactively offered, possibly through fear of judgement or reprisal. This does not mean support is not available; rather it suggests a breakdown in communication between the midwives in the room and those they are able to access for advice or assistance (Summary of FCTM Feb 2019)

supporting midwives who might feel that $\mathrm{CMC}$ is a risk in a challenging practice environment, particularly if there is minimal system change. Good leadership may also buffer external pressures to implement CMC in unrealistic timescales. Poor workforce engagement and poor leadership make it difficult to sustain positive change at the level of the individual midwife. Lack of organisational alignment with genuine woman centred care and reluctance or fear of increasing autonomy in relation to ways of working does not support CMC implementation or sustainability.

\section{Programme theory 2: relationships}

In the context of supportive organisational structures, CMC is founded on positive relationships between midwives and women [12, 38]. CMC aims to build relationships through frequent care contacts with the same midwife during a woman's care journey [12]. These relationships result in better clinical outcomes and care experiences for women [36, 38, 41, 44-54] and are thought to work through various mechanisms such as: trust [38, 47-49, 52, 53, 55]; feeling known [49, 51, 52, 56]; feeling empowered or confident [52, 53, 57], feeling relaxed [52]; emotional support [45, 55, 58, 59]; advocacy [60] and feeling safe [47]. Women in our evaluation said they liked having a relationship with their midwife, 'seeing a friendly face', feeling known and feeling confident in their midwives' abilities.

'One of the highlights was meet the midwife meetings. This left me and my partner very reassured and not scared about labour at all. My birth plan was known by the midwife delivering my baby. I think all of the above gave me the psychological comfort which helped me deliver my baby naturally and then breastfeed my baby from the very first hour of his life' (Women's Evaluation)

'Their' midwife not being present for their birth was disappointing for some but many accepted the early 'testing' stage of implementation. Perhaps of significant interest was how woman-midwife relationships impacted on midwives' practice by sustaining them and motivating them to provide high quality, individualised, womencentred and evidence-based care. The responsibility midwives felt for their women encouraged them to reflect on and change their approaches (See Theory 3). However, the responsibility could also increase their feelings of anxiety if women did not have a good outcome or care experience, even if this was beyond their control.

Returning to the ecological model, relationships can also be understood to be working at micro (midwifewoman), meso (midwife-midwife and MDT) and macro (organisational) levels to influence staff wellbeing [36, 43, 44, 48, 61-63], optimal care practices [64] and CMC's implementation and sustainability [43]. In our study CMC midwives were sustained and enabled by the relationships they developed within the team. These were particularly important at the outset when they were developing new ways of working. For midwives more used to working in the hospital context the team provided a sense of belonging. By contrast, relationships in the hospital or at the interfaces between the different models of care were more challenging. Again, positive relationships were sustaining for CMC midwives supporting their learning and ensuring they felt able to ask for help if required. Conversely, CMC midwives often felt watched and judged, which was undermining and disempowering. Feeling judged and perceiving a burden of high expectations from the maternity workforce through being the 'test team' for CMC meant they felt constantly alert and under pressure to perform well. In this context CMC midwives found it hard to ask for help, or if they did support was not always forthcoming, raising concerns about safe practice.

Key within relationships is trust [38, 47-49, 52, 53, 55], which also works within the workforce. Trusting relationships at all levels are fundamental to sustaining on-going implementation of $\mathrm{CMC}$, to midwife wellbeing and to women's positive experiences. More commonly, CMC midwives experienced a lack of trust, which played out through persistent questioning of skills, motives and commitment leading them to feel the need to continually justify their decision to volunteer for the change work and to prove worthy and hard working. Trust within the organisation is further discussed in Theory 3.

\section{Refined theory 2: relationships}

Within the context of effective leadership, CMC provides opportunities to develop trusting relationships between midwives and women and within small CMC teams. These relationships improve women's emotional wellbeing, support engagement with services and trigger changes to how midwives' practise (see Programme Theory 3). Negative relationships at any level disempower midwives and constrain the full implementation and sustainability of CMC. The effect of resistance to CMC on 
relationships and indirectly safety, should not be underestimated.

\section{Programme theory 3: midwifery practice}

Continuity midwives work differently from midwives in fragmented care [41, 51, 63]. This difference encompasses working more autonomously [36, 51], with greater responsibility [51, 65]; flexibly [44, 48, 51, 55], feeling in control [42, 66]; providing high-quality care that is evidence-based [41], holistic [45] and individualised/woman-centred $[44,53,56]$, and working with the full scope of midwifery practice $[1,39,51,55,67]$. This different way of practising results in greater job satisfaction and emotional wellbeing for midwives $[41,55]$. For example; working in $\mathrm{CMC}$ both enables and requires autonomy [41, 55], and professional autonomy results in better job satisfaction and wellbeing [7, 9, 40, 61].

Our evaluation data was consistent with the evidence that working to full scope of practice is enabled by CMC but constrained within fragmented models. Within our study the CMC midwives identified working across women's childbearing journey as important for providing woman-centred care and for increasing their midwifery role confidence, sense of empowerment [55] and job satisfaction [67]. However, we also found that autonomy, flexibility and scope of practice were affected by practice context, i.e. midwives need to be in control of their own workload to be able to practise flexibly and autonomously. This requires the organisation, more used to a transactional management style to trust in midwives' ability to manage their own caseloads and working patterns effectively. However, this relinquishing of power proved challenging thus hampering completely flexible and autonomous practice (see Theory 1). This has been identified by others; for example, in organisations, such as the NHS, 'midwifery practice may [...] be restricted by the misuse of policies, protocols and contractual or employers' obligations' [68], making autonomous practice potentially more difficult.

Implicit in the literature is the theory that exposure to the whole childbearing journey and working to full scope of practice has the potential to change midwives through personal and professional development, accountability, responsibility, reflective practice and being in control of their own diary and workload. We found that the women-midwife relationship is key to this practice transformation (see Theory 2). Positive experience of CMC then motivates midwives and managers to engage with the opportunity to implement CMC either by volunteering or actively supporting implementation from within the wider workforce. In our study, and the literature, midwives chose to trial (or work in) CMC models, which could suggest that they might be intrinsically different to other midwives who did not put themselves forward; for example, they may have a stronger philosophical commitment to physiological pregnancy and birth or woman centred care or have different personal attributes [51, 52, 69]. In support of this we identified that many of the midwives who volunteered to test CMC were motivated by a lack of belief in or negative experience of the current fragmented model. However, interviews with midwives and our field work with the teams also suggests that $\mathrm{CMC}$ changes the midwife:

'being involved in intrapartum care has really opened up my... made me more rounded as a midwife, I've been more interested in the care journey that the women will have through the intrapartum period. Normally [in previous role as community midwife] I would've discussed that with them but I might not have gone into as much detail or discussed the importance of really thinking about certain things and I wasn't as invested I suppose in the intrapartum, didn't see it as... it was the extra thing that I just probably never quite got round to. Whereas now I would see that as a bit more important than I would've thought before.' (CMC Midwife; Face to face interview)

Several studies have identified differences between midwives working in different models of care but were conducted after exposure to CMC, e.g. [7, 9, 11, 55]. However, two very small prospective studies $[36,70]$ showed positive changes in attitudes to professional role and role satisfaction following exposure to caseload/ MGP working.

Although our initial focus was on how practice changed within the team, our evaluation highlighted that system change was needed otherwise ground-up change was too constrained to be effective and sustained. Maternity systems designed for the fragmented model act against CMC, much like they did following Changing Childbirth [44] and proved challenging during our test of change. CMC midwives experienced this through lack of mutual understanding of roles, conflictual care pathways, unclear referral processes and difficulty working in a wider system that had remained unchanged. When these situations arose, midwives resistant to implementation of The Best Start [12] would hail them as good reason to stop the change rather than assist to resolve the issues, increasing the sense of division with the CMC midwives. This highlights the importance of securing a shared vision and commitment across the workforce, not just within the CMC teams.

\section{Refined theory 3: changing practice}

Within the context of effective leadership, trusting relationships and autonomous practice $\mathrm{CMC}$ midwives use 
the full scope of midwifery practice to provide flexible, woman-centred evidence-based care. This approach is not intrinsic since working in CMC and reflecting on their new approach to care changes how midwives practise. In the context of limited organisational support and poor relationships, attempting to embed CMC within the unchanged fragmented model in an unchanged system is not sustainable and efforts become increasingly fraught as CMC practice diverges from fragmented care.

Good leadership of the change management required for $\mathrm{CMC}$ requires belief, shared vision and effective and consistent communication. During our evaluation, inconsistencies in beliefs at all levels affected how people engaged with $\mathrm{CMC}$ e.g. whether to volunteer or to support implementation from within the wider workforce. Lack of belief in CMC or The Best Start was sometimes visible through inaction, reluctance to provide assistance or support, poor practice or incongruence between verbal and non-verbal communication.

\section{Refined programme theory}

Good leadership and effective change management which prioritises the development of trusting relationships across all levels of the organisation enables CMC to be implemented. These relationships along with shared values and beliefs then become the context that actively supports midwives to be autonomous practitioners who feel empowered and confident in their practice and committed to provide genuine, flexible, woman centred/individualised care to their caseload of women. These in turn result in improved professional role satisfaction, wellbeing and retention within the workforce. Flexible, woman centred/ individualised care in this context enables midwives to get to know women, their care needs and their personal circumstances which allows them to plan care appropriately, tailor information to individual needs and, through early detection of change or risk, treat or refer early resulting in improved clinical outcomes and greater satisfaction with care. Women centred care situated within a trusting relationship optimises biopsychosocial processes by empowering women, improving their emotional wellbeing and enhancing their engagement with the health services, Fig. 2.

\section{Discussion}

Effective leadership is essential for developing trusting relationships, the context in which CMC flourishes. Trusting relationships are the foundation on which CMC is built and become the cement that holds it together over time. Relationships matter, not only because women want them, but because it is the woman-midwife relationship that triggers change in women's behaviour [69] and midwives' practice resulting in better outcomes and care giving experience. The importance of womanmidwife relationships are already recognised, as are the supportive, sustaining and enabling relationships between midwives within CMC teams [48]. However, our study also suggests that good leadership operating across

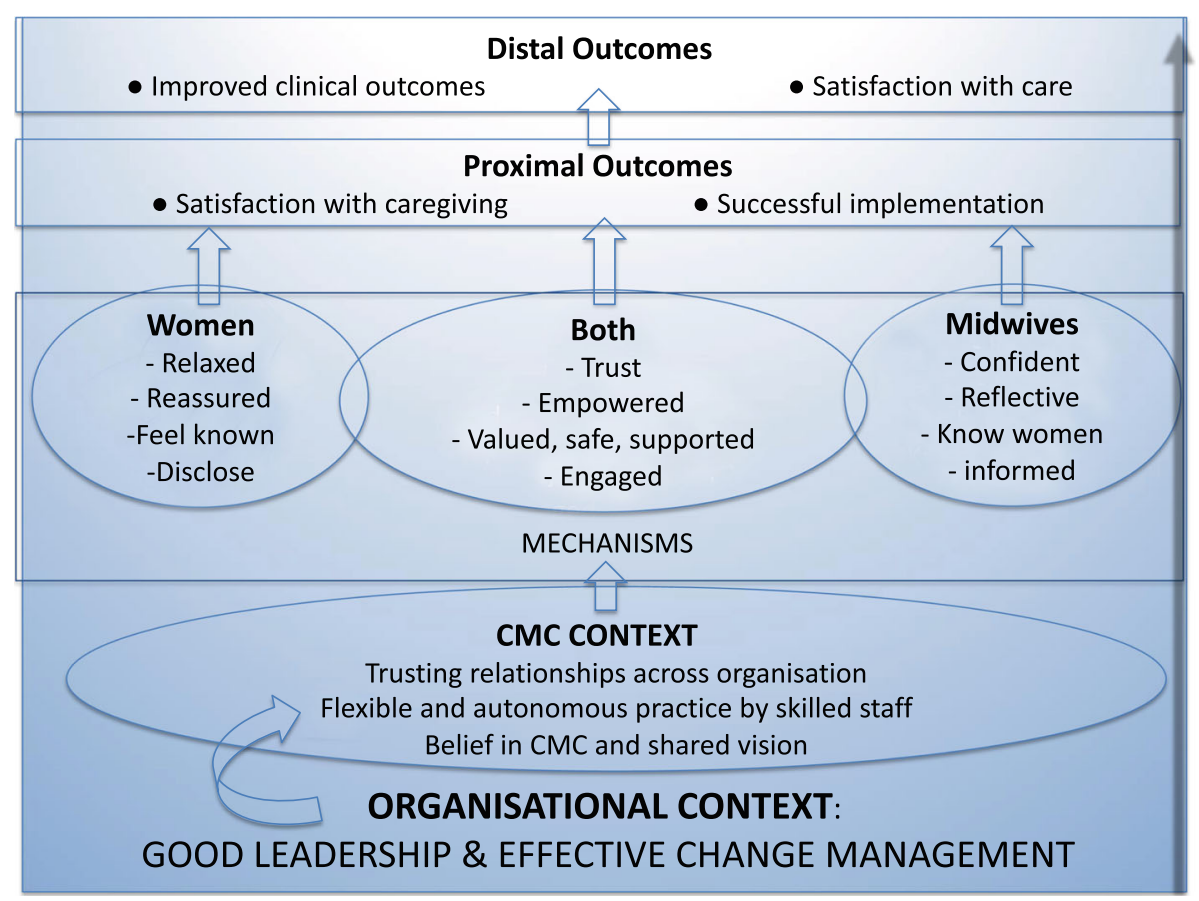

Fig. 2 Refined programme theory 
all levels is essential for building trusting relationships throughout the organisation, and that these relationships are required for midwives and others within the MDT to actively engage with $\mathrm{CMC}$ and change practice. Broken relationships (e.g. where managers do not trust midwives to act autonomously, where midwives do not trust managers to provide effective support or pressure to succeed) are barriers to practice change across all levels and to CMC implementation. This suggests that a shift from transactional to transformational leadership style within the organisation might help facilitate change.

Changes in practice, or personal and professional behaviours, of all professional groups (i.e. midwives and others within the MDT), across all levels and locations (i.e. CMC, wider workforce, organisational) are needed to accommodate $\mathrm{CMC}$ in the pre-existing fragmented model, while they co-exist. In this way CMC is a socially contingent complex intervention within a complex social system, i.e. its success relies on how people respond to CMC and how this affects their behaviour [71, 72]. Responses relate to personal beliefs or behaviours; those who believe in an intervention will enact their beliefs if the intervention provides resources or removes barriers [72]. All published studies identified, in keeping with this study, required midwives to volunteer to implement a new model of practice suggesting their reasoning already aligned with $\mathrm{CMC}$ and would implement change once any constraints were removed. Conversely midwives choosing to remain within the wider services may be less aligned with CMC indicating a need to change their reasoning or response to CMC as well as providing resources and opportunities [72]. Therefore, in a context where the operational implementation of $\mathrm{CMC}$ has been mainly rejected in advance [25] it is not enough to simply offer more opportunities to initiate or test more of the same. For example, rather than focusing only on behaviour, structural changes across the organisation and preparation of the future midwifery workforce might better support implementation and sustainability. We know that exposing student midwives to $\mathrm{CMC}$ during their undergraduate education increases their desire to work in CMC [73-75].

Allen et al., [69] identified 'Synergistic Health Engagement' as the mechanism by which optimal caseload midwifery (comprising philosophical commitment, institutional infrastructure and support, and personal attributes) modified the risks of preterm birth through women both attending and buying in (emotional investment and commitment) to services. In our study this mechanism might also explain the impact of caseloading on the midwife who through her relationship with women 'bought in' to $\mathrm{CMC}$ to ensure women had good experiences and outcomes.

Incorporating good evidence into practice is known to be slow [76] although in maternity care some evidence translates much quicker than others [77]. The inability to mainstream CMC, a high-quality evidence-based model supported by consumer demand, is particularly intransigent and [77] suggests that this might be because health professionals support change that aligns with their beliefs, biases and fears. Analysis of organisational context might also provide clues. Plamping [78] proposes that resistance to change in the NHS is due to four guiding principles which affect people's behaviour: 'can do should do'; 'doing means treatment'; 'treatment should fix', and 'I'm responsible'. She suggests that care is driven by treatment that fixes, which is why disease prevention and health promotion remain low priority despite our knowledge about societal determinants of ill health. Health professionals believing 'I'm responsible' will 'struggle for dominance' preventing cooperative or partnership working and excluding 'patients' from decision making [78]. The barriers to upscaling CMC become apparent when it is recognised that $\mathrm{CMC}$ requires autonomous midwives to work in partnership with women (first and foremost) and with other professional groups; to care or enable rather than 'fix', and to do less, but appropriately [79].

\section{Strengths and limitations}

This evaluation was informed by a large amount of data from a range of different sources. However, our focus was mainly on one health board setting which has its own specific contextual factors and history and may, therefore, privilege some concepts over others or favour an area specific perspective. Our findings resonate with much of the published literature and benefit from real time exploration of CMC implementation, suggesting that as per RE the mechanisms uncovered may be transferrable.

\section{Recommendations for practice}

- Good, visible leadership and effective change management strategies to change reasoning and to support those already bought in to CMC.

- Changes to organisational structures and practices across all levels, including relinquishing outdated controls that no longer serve a purpose.

- Trust in and empowerment of midwives as autonomous and responsible professionals.

- Ensure all models maximise relationships across the childbearing continuum. The possibility of a dose response should be considered and is worthy of further testing.

- Ensure exposure to the whole childbearing continuum and using full midwifery skillset as this changes practice. 
- Facilitate sustaining relationships within the CMC teams.

\section{Conclusions}

Trusting relationships are the foundation for $\mathrm{CMC}$, an evidence-based model of high-quality midwifery care that has better clinical outcomes, greater satisfaction with care and better caregiving experience. Implementing and sustaining CMC within the wider organisational context of the NHS requires significant reconfiguration of services at all levels. This requires effective leadership and cannot rely solely on ground up change. Trusting relationships are key and require to be nurtured and sustained to bring about organisational and cultural change to ensure CMC becomes the norm.

\section{Supplementary information}

Supplementary information accompanies this paper at https://doi.org/10. 1186/s12913-020-05159-9.

Additional file 1. Interview topic guide.

Additional file 2. Initial 'If... then' statements (pre-testing): 'If...then' statements, developed from the literature, The Best Start plan and stakeholder interviews.

Additional file 3. Preliminary $\mathrm{CMO}$ configurations: these were developed from the 'If...then' statements and tested in the on-going evaluation.

Additional file 4 Additional 'If ......then' statements from testing.

\section{Abbreviations}

AN: Antenatal; CMC: Continuity of midwife carer; CMO: Context mechanism outcome; FTE: Full time equivalent; LMC: Lead maternity carer; MDT: Multidisciplinary team; MGP: Midwifery group practice; NHS: National health service; PN: Postnatal; QI: Quality improvement; RCM: Royal college of midwives; RE: Realist evaluation; SG: Scottish government; UK: United Kingdom

\section{Acknowledgements}

We would like to acknowledge the role that the CMC team and their team leader played in helping to develop our understanding of implementing continuity within the NHS context; to women who provided feedback and to midwives and others within the wider context who contributed their thoughts, opinions and experiences.

\section{Authors' contributions}

RM developed the study, designed the methods and data collection methods, collected and analysed the data, developed and tested the programme theories and wrote the first draft of this paper. AAA developed and tested the programme theories, provided analytical input and insight into implementation of the model and the programme theories, provided guidance on the appropriate use of realistic evaluation, contributed significantly to the development of the first draft and contributed to subsequent drafts. SL developed audit and quality improvement data collection methods, the process of facilitating midwifery meetings and data collection tools; contributed to the development and testing of programme theories and brought new analytical insight to areas of programme implementation. CJHM provided guidance for on-going study development and contributed to the final draft; JM provided on-going support for study development; provided analytical input and insight into the development of programme theories and the use of realist evaluation and contributed to the drafting of this paper including the final version. All authors read and approved the final manuscript.

\section{Funding}

This research was funded through a NMAHP Clinical Academic Research Career programme which is a collaboration between NHS Scotland, NHS Lothian and Edinburgh Napier, Queen Margaret and Edinburgh Universities.

\section{Availability of data and materials}

The data used to inform this paper are presented within the paper or as supplementary files. Data sharing beyond this is not available as, other than interview transcripts, specific datasets were not generated by this study. Interview transcripts cannot be uploaded in full as this risks breaching confidentiality and because participants did not consent to full sharing of their transcripts.

\section{Ethics approval and consent to participate}

Ethics approval for this study was obtained from Edinburgh Napier University (SHSC 18014). We were advised that NHS Ethics was not considered necessary by the NHS Lothian Research Governance \& Management Approval office of the Academic and Clinical Central Office for Research and Development (ACCORD). All interview participants had chosen to participate in the interviews, were fully informed about the purpose of the study and provided written consent prior to the interviews taking place. Where this was by telephone, consent forms were emailed in advance to participants and verbal consent was reconfirmed at the time of the interview. Note all interviews were conducted with health professional and policy staff only.

\section{Consent for publication}

Not applicable.

\section{Competing interests}

The authors declare that they have no competing interests.

\section{Author details}

${ }^{1}$ School of Nursing \& Midwifery, Griffith University, Gold Coast Campus, Gold Coast, Queensland, Australia. ${ }^{2}$ School of Health, Edinburgh Napier University, Sighthill Campus, Edinburgh, Scotland. ${ }^{3}$ Nursing, Midwifery \& Allied Health Professions, NHS Education for Scotland, Westport, Edinburgh, Scotland. ${ }^{4} \mathrm{NHS}$ Lothian, Edinburgh, Scotland.

Received: 28 January 2020 Accepted: 26 March 2020

Published online: 15 April 2020

\section{References}

1. Renfrew MJ, McFadden A, Bastos MH, Campbell J, Channon AA, Cheung NF, et al. Midwifery and quality care: findings from a new evidence-informed framework for maternal and newborn care. Lancet. 2014;384.

2. Sandall J, Soltani H, Gates S, Shennan A, Devane D. Midwife-led continuity models versus other models of care for childbearing women. Cochrane Database Syst Rev. 2016:4:CD004667.

3. Allen J, Gibbons K, Beckmann M, Tracy M, Stapleton H, Kildea S. Does model of maternity care make a difference to birth outcomes for young women? A retrospective cohort study. Int J Nurs Stud. 2015;52.

4. Homer CSE, Leap N, Edwards N, Sandall J. Midwifery continuity of care in an area of high socio-economic disadvantage in London: a retrospective analysis of Albany midwifery practice outcomes using routine data (19972009). Midwifery. 2017:48:1-10.

5. McLachlan HL, Forster DA, Davey MA, Farrell T, Flood M, Shafiei T, et al. The effect of primary midwife-led care on women's experience of childbirth: results from the COSMOS randomised controlled trial. BJOG: An Int J Obstet Gynaecol. 2016;123(3):465-74.

6. McLachlan HL, Forster DA, Davey MA, Farrell T, Gold L, Waldenstrom U, et al. A randomised controlled trial of caseload midwifery for women at low risk of medical complications (COSMOS): women's satisfaction with care. J Paediatr Child Health. 2012:48.

7. Fenwick J, Sidebotham M, Gamble J, Creedy DK. The emotional and professional wellbeing of Australian midwives: a comparison between those providing continuity of midwifery care and those not providing continuity. Women Birth. 2018;31(1):38-43

8. Styles C, Kearney L, George K. Implementation and upscaling of midwifery continuity of care: the experience of midwives and obstetricians. Women Birth. 2019. https://doi.org/10.1016/j.wombi.2019.08.008. Accessed 25 Jan 2020 
9. Dixon L, Guilliland K, Pallant J, Sidebotham M, Fenwick J, McAra-Couper J, et al. The emotional wellbeing of New Zealand midwives: comparing responses for midwives in caseloading and shift work settings. NZ Coll Midwives J. 2017:53:9.

10. Bartholomew K, Morton SMB, Atatoa Carr PE, Bandara DK, Grant CC. Provider engagement and choice in the Lead maternity Carer system: evidence from growing up in New Zealand. Aust N Z J Obstet Gynaecol. 2015:55(4):323-30.

11. Jepsen I, Juul S, Foureur M, Sørensen EE, Nøhr EA. Is caseload midwifery a healthy work-form? - A survey of burnout among midwives in Denmark. Sex Reprod Healthc. 2017;11(Supplement C):102-6.

12. Scottish Government (SG). The Best Start: A Five-Year Forward Plan for Maternity and Neonatal Care in Scotland. 2017. Available: https://www.gov scot/publications/best-start-five-year-forward-plan-maternity-neonatal-carescotland-9781786527646/. Accessed 25 Jan 2020.

13. England NHS. Better births: a five year forward view for maternity care England: NHS England; 2016. Available: https://www.england.nhs.uk/wpcontent/uploads/2016/02/national-maternity-review-report.pdf. Accessed 25 Jan 2020

14. Department of Health. Changing Childbirth: Part I: Report of the Expert Maternity Group. London: HMSO; 1993.

15. Greenhalgh T, Wong G, Jagosh J, Greenhalgh J, Manzano A, Westhorp G, et al. Protocol—-the RAMESES II study: developing guidance and reporting standards for realist evaluation. BMJ Open. 2015;5(8):e008567.

16. Wong G, Westhorp G, Manzano A, Greenhalgh J, Jagosh J. Greenhalgh T. RAMESES II reporting standards for realist evaluations. BMC Med. 2016;14(1):96.

17. Pawson R, Tilley N. Realistic evaluation. London: Sage; 1997.

18. Greenhalgh T, Humphrey C, Hughes J, Macfarlane F, Butler C, Pawson R. How do you modernize a health service? A realist evaluation of whole-scale transformation in London. Milbank Q. 2009:87:391-416. https://doi.org/10. 1111/j.1468-0009.2009.00562.x.

19. NHS Employers. NHS Terms and Conditions (AfC) pay scales - Annual 2019. Available from: https://www.nhsemployers.org/pay-pensions-and-reward/ agenda-for-change/pay-scales/annual. Accessed 25 Jan 2020

20. Chief Nursing Officers of England Northern Ireland Scotland and Wales. Midwifery 2020: Delivering expectations. Cambridge: Midwifery 2020 Programme; 2010.

21. Royal College of Midwives (RCM). Caring for You Campaign: Survey Results. UK: Royal college of Midwives; 2016.

22. Royal College of Midwives. Why Midwives Leave. 2016B.

23. Barker K. Reasons why midwives leave. Br J Midwifery. 2016;24(12):1.

24. Royal College of Midwives. State of maternity services report 2018 Scotland. Edinburgh: Royal College of Midwives Scotland; 2018.

25. Mclnnes RJ, Hollins Martin CJ, MacArthur J. Midwifery continuity of carer: developing a realist evaluation framework to evaluate the implementation of strategic change in Scotland. Midwifery. 2018;66:103-10.

26. Hollins Martin CJ, MacArthur J, Martin CR, McInnes RJ. Midwives' views of changing to a continuity of midwifery care (CMC) model in Scotland: a baseline survey. Women Birth: J Aust Coll Midwives. 2019. https://doi.org/10. 1016/j.wombi.2019.08.005.

27. McLeroy KR, Bibeau D, Steckler A, Glanz K. An ecological perspective on health promotion programs. Health Educ Q. 1988;15(4):26.

28. Gibbs G. Learning by doing: a guide to teaching and learning methods. Oxford: Further Education Unit Oxford Polytechnic; 1988.

29. Key S, Marshall H, Hollins Martin CJ. The Scottish clinical supervision model for midwives. Br J Midwifery. 2019;27:9.

30. ACT Academy. Plan, Do, Study, Act (PDSA) cycles and the model for improvement: NHS Improvement; Undated [updated 25-01-2020]. Available from: https://improvement.nhs.uk/documents/2142/plan-do-study-act.pdf. Accessed 25 Jan 2020

31. Pawson R. The Basics of realist evaluation [Internet]; 2013 [cited 23-12-2019]. Podcast: 14 minutes. Available from: https://www.ramesesproject.org/Other_ resources.php. Accessed 8 Jan 2020

32. Mukumbang FC, Marchal B, Van Belle S, van Wyk B. "Patients are not following the [adherence] Club rules anymore": a realist case study of the antiretroviral treatment adherence Club, South Africa. Qual Health Res. 2018; 28(12):1839-57.

33. Saxbe DE. Birth of a new perspective? A call for biopsychosocial research on childbirth. Curr Dir Psychol Sci. 2017;26(1):81-6.

34. Brown $M$, Dietsch $E$. The feasibility of caseload midwifery in rural Australia: a literature review. Women Birth. 2013;26:e1-e4.
35. Burau V, Overgaard C. Caseload midwifery as organisational change: the interplay between professional and organisational projects in Denmark. BMC Pregnancy Childbirth. 2015;15(1):121

36. Collins CT, Fereday J, Pincombe J, Oster C, Turnbull D. An evaluation of the satisfaction of midwives' working in midwifery group practice. Midwifery. 2010;26(4):435-41.

37. Dawson K, McLachlan H, Newton M, Forster D. Implementing caseload midwifery: exploring the views of maternity managers in Australia - a national cross-sectional survey. Women Birth: J Aust Coll Midwives. 2016; 29(3):214-22.

38. Sandall J, Coxon K, Mackintosh N, Rayment-Jones H, Locock L, Page L (writing on behalf of the Sheila Kitzinger symposium). Relationships: the pathway to safe, high-quality maternity care Report from the Sheila Kitzinger symposium at Green Templeton College October 2015. Oxford: Green Templeton College; 2016. https://www.gtc.ox.ac.uk/wp-content/ uploads/2018/12/skp_report.pdf.

39. Sidebotham M, Fenwick J, Rath S, Gamble J. Midwives' perceptions of their role within the context of maternity service reform: an appreciative inquiry. Women Birth: J Aust Coll Midwives. 2015:28(2):112-20.

40. Yoshida Y, Sandall J. Occupational burnout and work factors in community and hospital midwives: a survey analysis. Midwifery. 2013;29:921-6.

41. Jepsen I, Mark E, Nøhr EA, Foureur M, Sørensen EE. A qualitative study of how caseload midwifery is constituted and experienced by Danish midwives. Midwifery. 2016;36:61-9.

42. Kirkham M. Resistance to continuity of Carer: our need for the naming of parts. Midwifery Matters. 2016;149:23-4.

43. Gilkison A, McAra-Couper J, Gunn J, Crowther S, Hunter M, Macgregor D, et al. Midwifery practice arrangements which sustain caseloading Lead maternity Carer midwives in New Zealand. NZ Coll Midwives J. 2015;51:6.

44. McCourt C, Stevens T. Continuity of carer: what does it mean and does it matter to midwives and birthing women? Can J Midwifery Res Pract. 2006;4: $10-20$.

45. Dahlberg U, Aune I. The woman's birth experience---the effect of interpersonal relationships and continuity of care. Midwifery. 2013;29(4):40715.

46. Josif CM, Barclay L, Kruske S, Kildea S. 'No more strangers': investigating the expeiences of women, midwives and others in the establishment of a new model of maternity care for remote dwelling aboriginal women in northern Australia. Midwifery. 2013;30:317-23.

47. Davison C, Hauck YL, Bayes SJ, Kuliukas LJ, Wood JG. The relationship is everything: Women's reasons for choosing a privately practising midwife in Western Australia. Midwifery. 2015;31(8):772-8.

48. Haines HM, Baker J, Marshall D. Continuity of midwifery care for rural women through caseload group practice: delivering for almost 20 years. Aust J Rural Health. 2015;23(6):339-45.

49. Jenkins MG, Ford JB, Todd AL, Forsyth R, Morris JM, Roberts CL. Women's views about maternity care: how do women conceptualise the process of 'continuity'? Midwifery. 2015;31(1):25-30.

50. Boyle S, Thomas H, Brooks F. Women's views on partnership working with midwives during pregnancy and childbirth. Midwifery. 2016;32:21-9.

51. Newton MS, McLachlan HL, Forster DA, Willis KF. Understanding the 'work' of caseload midwives: a mixed-methods exploration of two caseload midwifery models in Victoria, Australia. Women Birth: J Aust Coll Midwives. 2016;29(3):223-33

52. Allen J, Kildea S, Hartz DL, Tracy M, Tracy S. The motivation and capacity to go above and beyond: qualitative analysis of free-text survey responses in the M@NGO randomised controlled trial of caseload midwifery. Midwifery. 2017:50:148-56.

53. Perriman N, Davis DL, Ferguson S. What women value in the midwifery continuity of care model: a systematic review with meta-synthesis. Midwifery. 2018;62:220-9.

54. Hollander M, de Miranda E, Vandenbussche F, van Dillen J, Holten L. Addressing a need. Holistic midwifery in the Netherlands: A qualitative analysis. PloS One. 2019;14(7):e0220489-e.

55. Edmondson MC, Walker SB. Working in caseload midwifery care: the experience of midwives working in a birth Centre in North Queensland. Women And Birth: J Aust Coll Midwives. 2014;27(1):31-6.

56. Beake S, Acosta L, Cooke P, McCourt C. Caseload midwifery in a multi-ethnic community: the women's experiences. Midwifery. 2013;29(8):996-1002. 
57. Leap N, Sandall J, Buckland S, Huber U. Journey to confidence: Women's experiences of pain in labour and relational continuity of care. Journal of Midwifery Women's Health. 2010;55(3):234-42.

58. Huber U, Sandall J. Continuity of carer, trust and breastfeeding. MIDIRS Midwifery Dig. 2006;16(4):445-9.

59. Hunter B, Berg M, Lundgren I, Olafsdottir OA, Kirkham M. Relationships: the hidden threads in the tapestry of maternity care. Midwifery. 2008; 24(2):132-7.

60. Finlay S, Sandall J. "Someone's rooting for you": continuity, advocacy and street-level bureaucracy in UK maternal healthcare. Soc Sci Med. 2009;69(8): 1228-35.

61. Cramer E, Hunter B. Relationships between working conditions and emotional wellbeing in midwives. Women Birth. 2019:32(6):521-32.

62. McAra-Couper J, Gilkison A, Crowther S, Hunter M, Hotchin C, Gunn J. Partnership and reciprocity with women sustain Lead maternity Carer midwives in practice. NZ Coll Midwives J. 2014;49:27-31.

63. Stevens T, McCourt C. One-to-one midwifery practice part 3: meaning for midwives. Br J Midwifery. 2002;10:111-5.

64. Schölmerich VL, Posthumus AG, Ghorashi H, Waelput AJ, Groenewegen P, Denktaş S. Improving interprofessional coordination in Dutch midwifery and obstetrics: a qualitative study. BMC Pregnancy Childbirth. 2014;14:145.

65. Huber US, Sandall J. A qualitative exploration of the creation of calm in a continuity of carer model of maternity care in London. Midwifery. 2009; 25(6):613-21.

66. Sandall J. Midwives' burnout and continuity of care. Br J Midwifery. 1997;5: 107-11.

67. Menke J, Fenwick J, Gamble J, Brittain H, Creedy DK. Midwives' perceptions of organisational structures and processes influencing their ability to provide caseload care to socially disadvantaged and vulnerable women. Midwifery. 2014;30(10):1096-103.

68. International Confederation of Midwives. Philosophy and Model of Midwifery Care 2014. Available: https://www.internationalmidwives.org/ourwork/policy-and-practice/philosophy-and-model-of-midwifery-care.html. Accessed 8 Jan 2020.

69. Allen J, Kildea S, Stapleton H. How optimal caseload midwifery can modify predictors for preterm birth in young women: integrated findings from a mixed methods study. Midwifery. 2016;41:30-8.

70. Newton MS, McLachlan HL, Willis KF, Forster DA. Comparing satisfaction and burnout between caseload and standard care midwives: findings from two cross-sectional surveys conducted in Victoria Australia. BMC Pregnancy and Childbirth. 2014;14(1):426.

71. Jagosh J. Realist evaluation and an architectural understanding of health and social Programmes. Sem Cent Adv Realist Eval Synth (CARES). 2019. Online Seminar. Available on https://youtu.be/siiHTOb9olo. Accessed 2 Apr 2020.

72. Westhorp G. Realist impact evaluation: an introduction. London: Overseas Development Institute; 2014.

73. Browne J, Taylor J. 'It's a good thing...': Women's views on their continuity experiences with midwifery students from one Australian region. Midwifery. 2014;30(3):e108-e14.

74. Carter A, McDonald-Smith K, Wilkes E, O'Luanaigh P, Gamble J, Creedy D. Midwifery students embedded in continuity: Students' and mentors' experiences. Women Birth. 2015;28:S10-S

75. Gamble J, Sidebotham M, Gilkison A, Davis D, Sweet L. Acknowledging the primacy of continuity of care experiences in midwifery education. Women Birth: J Aust Coll Midwives. 2019;33(2):111-8.

76. Morris ZS, Wooding S, Grant J. The answer is 17 years, what is the question: understanding time lags in translational research. J R Soc Med. 2011;104(12): 510-20.

77. Homer CSE. Getting evidence into practice - managing hares and tortoises. Wome Birth. 2018;31(6):431-2.

78. Plamping D. The NHS's 50 anniversary. Change and resistance to change in the NHS. Br J Med. 1998;317(7150):3.

79. Miller S, Abalos E, Chamillard M, Ciapponi A, Colaci D, Comandé D, et al. Beyond too little, too late and too much, too soon: a pathway towards evidence-based, respectful maternity care worldwide. Lancet. 2016; 388(10056):2176-92.

\section{Publisher's Note}

Springer Nature remains neutral with regard to jurisdictional claims in published maps and institutional affiliations.

Ready to submit your research? Choose BMC and benefit from:

- fast, convenient online submission

- thorough peer review by experienced researchers in your field

- rapid publication on acceptance

- support for research data, including large and complex data types

- gold Open Access which fosters wider collaboration and increased citations

- maximum visibility for your research: over $100 \mathrm{M}$ website views per year

At BMC, research is always in progress.

Learn more biomedcentral.com/submissions 